\title{
Analysis of clinical features, treatment response, and prognosis among 61 elderly newly diagnosed multiple myeloma patients: a single-center report
}

\author{
$\mathrm{Na} \mathrm{An}^{\dagger}$, Xin $\mathrm{Li}^{\dagger}$, Man Shen, Shilun Chen and Zhongxia Huang ${ }^{*}$
}

\begin{abstract}
Background: We identified the clinical features of 61 cases of multiple myeloma (MM) patients over 65 years and analyzed the treatment and prognosis of the era of new drugs in elderly patients.

Methods: We identified 61 newly diagnosed symptomatic multiple myeloma (NDMM) among elderly Chinese patients more than 65 years old diagnosed from 2006 to 2012.

Results: Of the 205 consecutive MM patients whom we reviewed, 61 (29.76\%) cases were NDMM patients aged more than 65 years and the others were younger than 65 years old. Among them, 40 (65.6\%) cases were in end-stage (ISS stage III); meanwhile, 19 (31.2\%) cases of them had MM with extramedullary plasmacytoma (EMP), observed in $42.1 \%$ patients at diagnosis, and the top three incidence of position were spinal canal, pleural, and soft tissue. In the whole column, the median follow-up was 38 months and median age was 72.5 years. Patients received bortezomib- or thalidomide-containing regimens as initial therapy. Comparing the two treatment groups, the complete remission $(\mathrm{CR}) /$ near-complete remission $(\mathrm{nCR})$ rate was significantly higher in the bortezomib-containing regimens (61.5 vs.18.18\%, $P=0.001)$, no difference in progression-free survival (PFS) and overall survival (OS). Patients of age over 75 years had shorter OS than those of age over 65 years (49 vs. 24 months, $P=0.001$ ). The patients with EMP had shorter OS than those without EMP in two age groups (32 vs. 42 and 15 vs. 24 months, $P=0.017$ and 0.024 , respectively).
\end{abstract}

Conclusions: The results highlight that patients over 75 years and MM with EMP have a poorer outcome. While the CR rate is higher in bortezomib-containing regimens, no significant improvement is noted in respect to the survival outcomes; also, it cannot overcome the negative influence on survival of age and MM with EMP in elderly patients.

Keywords: Multiple myeloma, Elderly patients, Bortezomib, Overall survival

\section{Background}

Multiple myeloma (MM) is still an incurable disease, representing the second most common hematologic malignancy worldwide [1]. In Asian countries, there is growing evidence that recognition of $\mathrm{MM}$ is increasing rapidly, doubling of $\mathrm{MM}$ incidence in the last 10 years [2-4]. In recent years, application of new drugs improves the prognosis of $\mathrm{MM}$ patients, including the elderly [5]. However, old patients often present with comorbid conditions, which may decrease their ability to

\footnotetext{
* Correspondence: huangzhongxia@sina.com

${ }^{\dagger}$ Equal contributors

Multiple myeloma medical center of Beijing, Department of Hematology, Beijing Chao-yang Hospital, Capital Medical University, 5 Jingyuan Road, Shijingshan District, Beijing 100043, China
}

tolerate myelosuppressive regimens; age-related survival inequality was also observed [6]. Currently, limited information is available on the treatment of newly diagnosed symptomatic multiple myeloma (NDMM) among elderly Chinese patients. In this paper, initial treatment response and survival of 61 cases of NDMM in elderly Chinese patients are analyzed. This represents one of the larger series examining the outcomes of elderly patients with NDMM of a single center report from China in recent years.

\section{Methods}

The clinical data of 61 cases of NDMM elderly patients had been diagnosed from Beijing Chao-Yang Hospital 
(western campus) from March 2006 to March 2012. They were divided into two groups as age: group A (age $\geq 65,65-74$ years) and group B (age $\geq 75$ years). The diagnosis was based on the International Myeloma Working Group (IMWG) diagnostic criteria. Patients who had an organ involvement with light-chain amyloidosis at the time of diagnosis were not included in the current analysis. MM patients with extramedullary plasmacytoma (EMP) was observed in $42.1 \%$ patients at diagnosis and $57.9 \%$ patients during the disease course, detected by magnetic resonance imaging (MRI), computed tomography (CT), and/or histopathological analysis of biopsy specimens.

In our study, patients received initial therapy with regimens containing bortezomib or thalidomide, for 1-8 cycles. The mean duration of bortezomib-containing regimens was 4 cycles. In patients achieving a complete response (CR) or very good partial response (VGPR), the regimen was repeated for 2-4 cycles as consolidation therapy. In the absence of this, the treatment regimen was modified. Maintenance therapy when utilized was

Table 1 General clinical characteristics of 61 cases of elderly NDMM patients

\begin{tabular}{|c|c|c|c|}
\hline Characteristics & Overall & Groups & \\
\hline Age (years) & $72.5(n=61)$ & $\mathrm{A}(\geq 65, n=37)$ & $\mathrm{B}(\geq 75, n=24)$ \\
\hline \multicolumn{4}{|l|}{ Gender } \\
\hline Male & $38(62.3 \%)$ & $23(62.2 \%)$ & $14(37.8)$ \\
\hline Female & $23(37.7 \%)$ & $14(37.8 \%)$ & $10(41.7)$ \\
\hline Calcium >11 mg/dl & $4(6.6 \%)$ & $2(5.4 \%)$ & $2(8.3 \%)$ \\
\hline Creatinine $>2.0 \mathrm{mg} / \mathrm{dl}$ & $\begin{array}{l}12 \\
(19.67 \%)\end{array}$ & $7(18.9 \%)$ & $5(20.8 \%)$ \\
\hline Hemoglobin <10 g//L & $48(78.7 \%)$ & $28(75.7 \%)$ & $20(83.3 \%)$ \\
\hline Bone lesions & $58(95.1 \%)$ & $35(94.6 \%)$ & $23(95.8 \%)$ \\
\hline \multicolumn{4}{|c|}{ M component at diagnosis } \\
\hline $\lg G$ & $29(47.5 \%)$ & $16(43.2 \%)$ & $13(54.2 \%)$ \\
\hline $\lg A$ & $16(26.2 \%)$ & $11(29.7 \%)$ & $5(20.8 \%)$ \\
\hline $\lg D$ & $2(3.3 \%)$ & $2(5.4 \%)$ & 0 \\
\hline Light chain & $13(21.3 \%)$ & $8(21.6 \%)$ & $5(20.8 \%)$ \\
\hline Non-secretory & $1(1.6 \%)$ & 0 & $1(4.2 \%)$ \\
\hline \multicolumn{4}{|l|}{ Stage of ISS } \\
\hline I & $1(1.6 \%)$ & 0 & $1(4.2 \%)$ \\
\hline$\|$ & $20(32.8 \%)$ & $13(35.1 \%)$ & 7 (29.2 \%) \\
\hline III & $40(65.6 \%)$ & $24(64.9 \%)$ & $16(66.7 \%)$ \\
\hline MM with EMP & $19(31.2 \%)$ & $12(32.4 \%)$ & 7 (29.2 \%) \\
\hline \multicolumn{4}{|c|}{ Abnormal genetics testing } \\
\hline $\begin{array}{l}\text { G-banded karyotype } \\
\text { testing }\end{array}$ & $4(6.6 \%)$ & $3(11.5 \%)$ & $1(3.8 \%)$ \\
\hline $\mathrm{FISH}$ & $13(21.3 \%)$ & 7 (26.9 \%) & $5(19.2 \%)$ \\
\hline
\end{tabular}

Table 2 Clinical characteristics of MM with EMP

\begin{tabular}{|c|c|c|c|}
\hline Characteristics & $\begin{array}{l}\text { Overall } \\
(n=19)\end{array}$ & $A(\geq 65)$ & $B(\geq 75)$ \\
\hline Age & $72(65-81)$ & $69(65-73)$ & $77(75-81)$ \\
\hline \multicolumn{4}{|l|}{ Gender, n (\%) } \\
\hline Male & 10 (52.6\%) & 7 (36.8 \%) & $3(15.8 \%)$ \\
\hline Female & $9(47.4 \%)$ & $5(26.3 \%)$ & $4(21.1 \%)$ \\
\hline \multicolumn{4}{|l|}{ Heavy chain, $n(\%)$} \\
\hline $\lg G$ & $9(47.4 \%)$ & $6(31.6 \%)$ & $3(15.8 \%)$ \\
\hline $\lg A$ & $6(31.6 \%)$ & $3(15.8 \%)$ & $3(15.8 \%)$ \\
\hline \multicolumn{4}{|l|}{ Light chain, $n$ (\%) } \\
\hline $\mathrm{k}$ light chain & 1 (5.3\%) & $1(5.3 \%)$ & 0 \\
\hline$\lambda$ light chain & $2(10.6 \%)$ & $1(5.3 \%)$ & $1(5.3 \%)$ \\
\hline$\beta 2 \mathrm{MG} \geq 5.5 \mathrm{mg} / \mathrm{l}, n(\%)$ & 14 (73.7 \%) & $10(52.6 \%)$ & $4(21.1 \%)$ \\
\hline \multicolumn{4}{|l|}{ Sites of EMP, $n(\%)$} \\
\hline 1. Spinal canal & 10 (52.6\%) & $8(42.1 \%)$ & $2(10.5 \%)$ \\
\hline 2. Pleura & $5(26.3 \%)$ & 0 & $5(26.3 \%)$ \\
\hline 3. Soft tissue & $2(10.5 \%)$ & $2(10.5 \%)$ & 0 \\
\hline $\begin{array}{l}\text { More than two } \\
\text { sites, } n(\%)\end{array}$ & $4(21.1 \%)$ & $4(21.1 \%)$ & 0 \\
\hline $\begin{array}{l}\text { Plasma cell } \\
\text { percentage, } n(\%)\end{array}$ & $37.2(2-91)$ & $37(2-91)$ & $37.5(18.5-46.5)$ \\
\hline \multicolumn{4}{|l|}{$\begin{array}{l}\text { Abnormal genetics } \\
\text { testing, } n(\%)\end{array}$} \\
\hline $\begin{array}{l}\text { G-banded karyotype } \\
\text { testing }\end{array}$ & $2(33.3 \%)$ & $1(16.7 \%)$ & $1(16.7 \%)$ \\
\hline FISH & 4 (66.7 \%) & 0 & 4 (66.7\%) \\
\hline
\end{tabular}

mostly with thalidomide $100 \mathrm{mg} /$ day; the other maintenance regimens included small doses of corticosteroids or lenalidomide. The patients who were unable to tolerate the side effects or were in poor physical condition did not receive maintenance therapy.

Aspirin or low molecular weight heparin to prevent venous thrombosis was routinely used in patients without contraindications. Herpes zoster prophylaxis was routinely used while patients were on bortezomib. Bisphosphonates were used intravenously for myeloma bone prophylaxis monthly.

In this elderly cohort, the patients who were diagnosed as plasma cell leukemic and undergo autotransplant were specifically excluded. Lenalidomide is approved on sale in China in June 2013, but it has not been approved for treatment with the newly diagnosed myeloma patients. So in the current study, the patients received lenalidomide only as maintenance.

The patients were assessed after the completion of 2 cycles of chemotherapy. Responses were graded using the IMWG Uniform Response Criteria, and adverse events were assessed according to the National Cancer 
Institute Common Terminology Criteria for Adverse Events (CTCAE) version 3.0.

\section{Ethics statement}

The study was approved by the Ethics Committee of Beijing Chao-yang Hospital, Capital Medical University, and follow-up information was obtained with consent of the patients. All aspects of the study were conducted in accordance with the principles of the Declaration of Helsinki.

We used SPSS19.0 (SPSS Inc., Chicago, IL, USA) statistical software for data analysis, and the Kaplan-Meier method was used to assess overall survival (OS) and

Table 3 Genetics test results of the elderly NDLM patients

\begin{tabular}{|c|c|c|}
\hline $\begin{array}{l}\text { Patient } \\
\text { No. }\end{array}$ & Chromosome & FISH \\
\hline 1 & 13 q14 and $14 q 32$ & No FISH \\
\hline 2 & $46 x x$ & Amplification of 1q21 \\
\hline 3 & $46 x x$ & IGH/FGFR3+ \\
\hline 4 & $46 x x$ & Negative \\
\hline 5 & $46 x x$ & Amplification of 1q21 \\
\hline 6 & $46 x y$ & $\begin{array}{l}\text { Amplification of 1q21, } \\
\text { IGH/FGFR3+ }\end{array}$ \\
\hline 7 & $46 x y$ & Negative \\
\hline 8 & $46 x x$ & $17 p-$ \\
\hline 9 & $46 x y$ & Negative \\
\hline 10 & $46 x x$ & $\begin{array}{l}\text { Amplification of 1q21 } \\
\text { and CCND1 }\end{array}$ \\
\hline 11 & $\begin{array}{l}\text { Complex karyotype } \\
\text { abnormalities }\end{array}$ & Negative \\
\hline 12 & $46 x y$ & $17 p-$, amplification of $\mathrm{IGH}$ \\
\hline 13 & $46 x y$ & Amplification of 1 q21 \\
\hline 14 & $46 x y$ & $\begin{array}{l}\text { Amplification of 1q21, } \\
\text { I GH and FGFR3 }\end{array}$ \\
\hline 15 & $46 x y$ & No FISH \\
\hline 16 & $46 x y$ & No FISH \\
\hline 17 & $46 x y$ & Negative \\
\hline 18 & $46 x x$ & No FISH \\
\hline 19 & $46 x x$ & Amplification of 1q21 \\
\hline 20 & $46 x x$ & No FISH \\
\hline 21 & $46 x y$ & $\begin{array}{l}\text { Amplification of 1q21 } \\
\text { and IGH/MAF+ }\end{array}$ \\
\hline 22 & $46 x y$ & Negative \\
\hline 23 & $\begin{array}{l}\text { Hypodiploid of chromosome } \\
\text { abnormalities }\end{array}$ & $\begin{array}{l}\text { 17p-, } 13 q-\text {-, and } \\
\text { amplification of IGH }\end{array}$ \\
\hline 24 & $46 x y$ & Negative \\
\hline 25 & $\begin{array}{l}\text { Complex chromosome } \\
\text { abnormalities }\end{array}$ & $\begin{array}{l}\text { Amplification of 1q21, } \\
17 p-\text { IGH/CCND1+ }\end{array}$ \\
\hline
\end{tabular}

Twenty-five cases of patients with a chromosome examination, including four cases of abnormal chromosomal changes. Nineteen patients had FISH testing; among them, 13 patients had abnormal FISH changes progression-free survival (PFS). $P<0.05$ (log-rank test) was considered statistically significant.

\section{Results}

Of all the 61 cases of patients, the median age at diagnosis was 72.5 years. The male and the female were $62.3 \%$ $(38 / 61)$ and $37.7 \%(23 / 61)$ cases, respectively. In terms of International Staging (ISS), $65.6 \%$ (40/61) and $32.8 \%$ $(20 / 61)$ and $1.6 \%(1 / 61)$ cases were at stage III, II, and I, respectively. Among them, $31.2 \%$ (19/61) cases were diagnosed as MM with EMP, and the top three incidence of position were spinal canal, pleural, and soft tissue. The median follow-up was 38 months (24-96) at the last follow-up. The general clinical characteristics were provided in Tables 1, 2, and 3.

Patients received bortezomib-containing regimens as follows: bortezomib (Velcade, $\mathrm{V}$ or P) and dexamethasone (D) or VD with cyclophosphamide (VCD) or with adriamycin (A) (PAD). Patients received thalidomide-containing regimens as follows: TAD or melphalan $(\mathrm{M})$ and prednisone (P) thalidomide (T) (MPT) and CTD. Among the above regimens, bortezomib $\left(1.0-1.3 \mathrm{mg} / \mathrm{m}^{2}\right)$ was given intravenously or subcutaneously on days $1,4,8$, and 11 of a 21-day/cycle or weekly and dexamethasone $10-20 \mathrm{mg} /$ day on days $1,4,8$, and $11 /$ cycle or weekly, cyclophosphamide $\left(200 \mathrm{mg} / \mathrm{m}^{2}\right)$ and adriamycin $\left(9 \mathrm{mg} / \mathrm{m}^{2}\right)$. Melphalan $\left(4 \mathrm{mg} / \mathrm{m}^{2} /\right.$ day $)$ and prednisone $\left(40 \mathrm{mg} / \mathrm{m}^{2} /\right.$ day $)$ were administered orally on days 1-7, PO. Among CTD regimen, cyclophosphamide was given on days $1-4 / 15-18$ intravenously and dexamethasone $10-20 \mathrm{mg}$ /day on days $1-4 / 15-18, \mathrm{PO}$, and thalidomide $(100 \mathrm{mg})$ was administered orally each day. In this study, treatment regimens were heterogeneous, but VD or TAD was the most commonly used.

Table 4 Adverse events (AEs)

\begin{tabular}{|c|c|c|}
\hline Adverse events (AEs) & $\begin{array}{l}\text { Bortezomib-containing } \\
\text { regimens }\end{array}$ & $\begin{array}{l}\text { Thalidomide-containing } \\
\text { regimens }\end{array}$ \\
\hline Case (\%) & $(n=39)$ & $(n=22)$ \\
\hline $\begin{array}{l}\text { Gastrointestinal } \\
\text { symptoms }\end{array}$ & $23(60 \%)$ & 7 (31.8 \%) \\
\hline $\begin{array}{l}\text { Infection (bacterial or/ } \\
\text { and fungal) }\end{array}$ & 12 (30.8\%) & $14(63.6 \%)$ \\
\hline Peripheral neuropathy & 12 (30.8 \%) & $6(27.3 \%)$ \\
\hline Cytopenia & $8(20.5 \%)$ & $4(18.2 \%)$ \\
\hline Hyperglycemia & $5(12.8 \%)$ & $5(22.7 \%)$ \\
\hline Thrombosis & 0 & $3(13.6 \%)$ \\
\hline Herpes zoster & $2(5.1 \%)$ & 0 \\
\hline Arrhythmia & $1(2.6 \%)$ & $1(4.6 \%)$ \\
\hline Rash & 1 (2.6\%) & 1 (4.6\%) \\
\hline
\end{tabular}


Table 5 Comparison of efficacy of the two treatment options groups

\begin{tabular}{llll}
\hline Treatment options & Cases & ORR\% & CR/n CR\% \\
\hline Bortezomib-containing regimens & 39 & 94.9 & 61.51 \\
Thalidomide-containing regimens & 22 & 86.4 & 18.2 \\
$P$ value & & $P>0.05$ & $P=0.001$
\end{tabular}

Comparison of bortezomib-containing regimens and thalidomide-containing regimens treatment options. There were significant difference $(P=0.001)$ in $\mathrm{CR} / \mathrm{nCR}$ and no significant difference in ORR

\section{Adverse events}

Adverse events (AEs) of two treatment groups were shown in Table 4; the top three were gastrointestinal symptoms, infection, and peripheral neuropathy. 1-2 grades and tolerated gastrointestinal reactions were found in 30 cases; these included nausea, vomiting, bloating, constipation, diarrhea, and anorexia, of 23 (60\%) cases occurred in the bortezomib-containing regimen groups. All 26 cases suffered infection, most of which were lung bacterial or/and fungal infection, of 14 (63.6\%) cases occurred in the thalidomide-containing regimens groups, especially the patients application of TAD regimen treatment. Eighteen cases suffered 1-2 grades of peripheral neuropathy, and its incidence was similar in both treatment groups of approximately $30 \%$. These included numbness in hand and foot. The number of patients who suffered thrombocytopenia, elevated blood glucose (among them three cases had steroid diabetes because of glucocorticoid), and thrombosis were 12, 10, and 3. The others included herpes zoster infection of grades 3-4 (two cases), arrhythmia (two cases), and rash (two cases).

\section{Treatment response}

Comparing two treatment groups, the ORR of bortezomibcontaining regimens was $94.9 \%(37 / 39)$ and $\mathrm{CR} / \mathrm{nCR}$ was $61.5 \%(24 / 39)$. For the thalidomide-containing regimens, its ORR was $86.4 \%(19 / 22)$ and CR/nCR rate was $18.2 \%$ $(4 / 22)$; there were significant difference $(P=0.001)$ in $C R /$ nCR and no significant difference in ORR (Table 5).

For two age groups, overall response rate (ORR) was $94.6 \%(35 / 37)$ and $\mathrm{CR} / \mathrm{nCR}$ rate was $48.7 \%(18 / 37)$ in group A. ORR was $87.5 \%(21 / 24)$ and $\mathrm{CR} / \mathrm{nCR}$ rate was $41.7 \%$ in group $B$; there was no significant difference between the two of them.

Of $42.2 \%(8 / 19)$ cases of patients who suffered MM with EMP at diagnosis, seven cases received bortezomibcontaining regimen treatment; their ORR was $85.5 \%$ and CR was $28.6 \%$.

\section{Survival outcomes}

Between the two age groups, OS was 37 and 19 months and the median PFS was 22 and 14.5 months, respectively, for group A and group B. There was a significant difference in OS $(P=0.001)$ but no difference in PFS (Fig. 1). OS rates at $1,2,3,4$, and 5 years were 82, 73, 60,35 , and $28 \%$, respectively, in group A. Meanwhile, OS rates at $1,2,3$, years were 54,30 , and $20 \%$, respectively, in group B.

The patients with EMP had shorter OS than those without EMP in two age groups; their OS was 32 vs. 42 in group $\mathrm{A}$ and 15 vs. 24 months in group $\mathrm{B}(P=0.017$ and 0.024 ), respectively (Fig. 2a, b).

Comparing the two treatment options of bortezomibcontaining and thalidomide-containing regimens in group A, OS was 41 vs. 36.5 months and PFS was 23 vs. 16.5. So

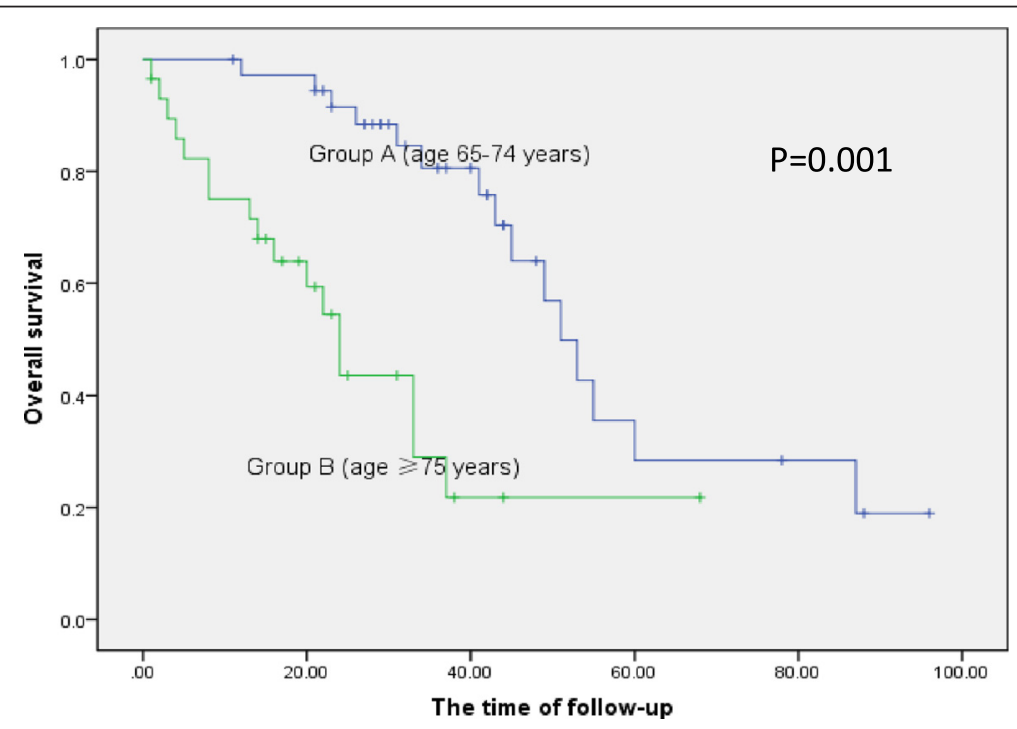

Fig. 1 Survival curves in two age groups. There was significant difference in OS between two age groups ( $P=0.001)$ but no difference in PFS 
a
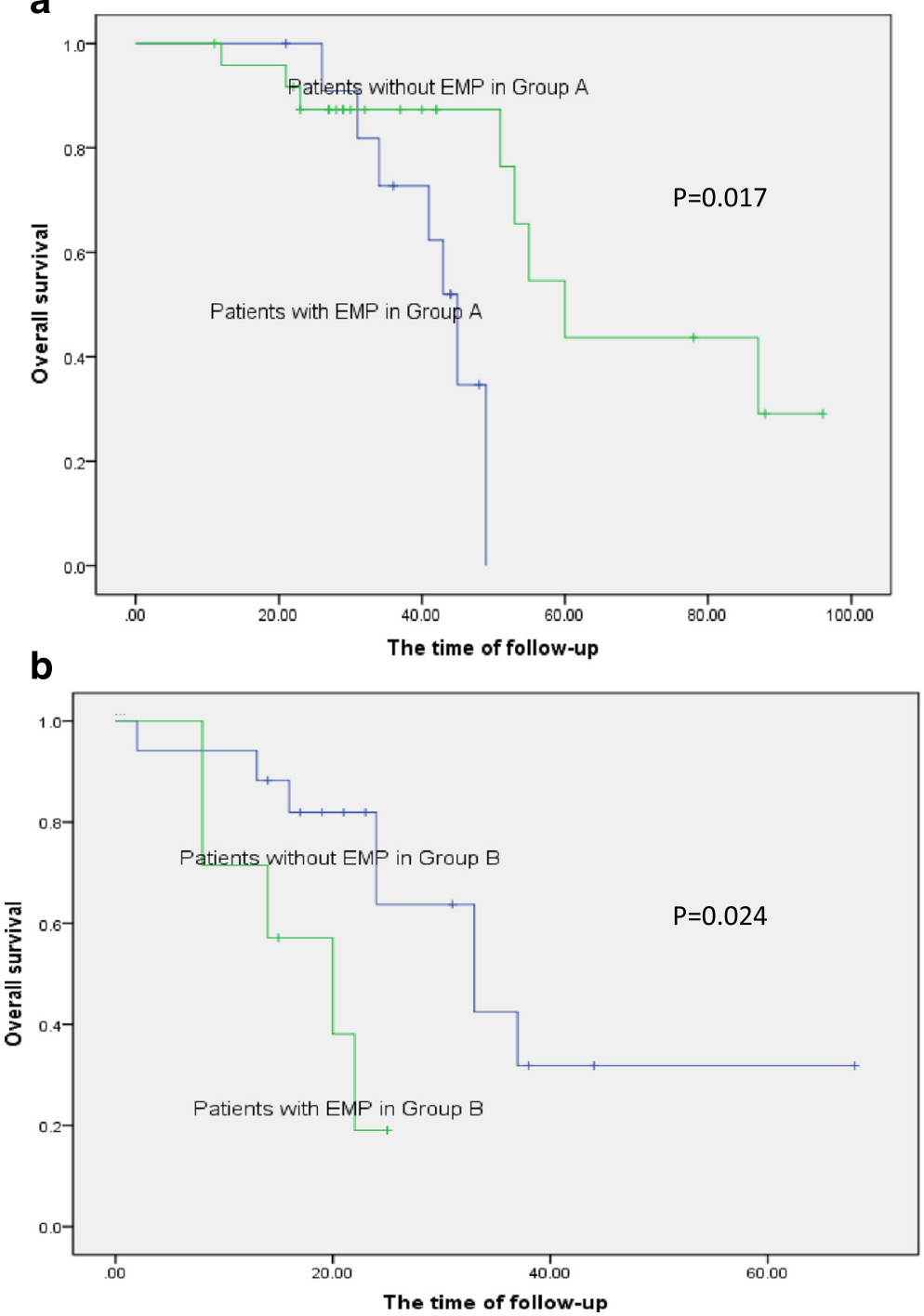

Fig. 2 Survival curves in regard to EMP in two age groups. a OS of group A in regard to EMP. $\mathbf{b}$ OS of Group B in regard to EMP. The patients with EMP had shorter OS than patients without EMP in two age groups $A$ and $B(P=0.017$ and 0.024$)$, respectively

did in group B; OS was 24 vs. 19 months and PFS was 16 vs. 11 months. There were no differences in these two treatment options for OS and PFS.

\section{Discussion}

Of the 205 consecutive MM patients whom we reviewed, 61 (29.76\%) cases were NDMM patients aged more than 65 years and the others were younger than 65 years old. Among them, 40 (65.6\%) cases were in end-stage (ISS stage III) and 19 (31.2\%) cases of them had MM with EMP. Our results are consistent with other reports from Chinese patients; the median age of onset and incidence of MM with EMP are different from the western countries although there have been no accurate estimates of incidence of MM in China [2, 4, 7-10].

In the current study, comparing the bortezomibcontaining regimens and thalidomide-containing regimens, the rate and degree of remission all favored the efficacy of bortezomib [5, 10-17], regardless of the age.

Nevertheless, further analysis found that age and MM with EMP had a negative impact on survival. Therefore, the high remission rate benefited by bortezomib did not transfer into a survival advantage. It can be seen among patients $\geq 75$ years, whose PFS and OS were worse compared to those over 65 years, such results clearly indicated greater influence on the survival of the elderly patients, especially the patients of age over 75 years [6, 15]. For 
patients with EMP, either two different age groups, whose OS was worse with EMP or infiltration of extramedullary patients, further confirmed MM with EMP adversely affect the prognosis $[7,18]$.

There was no significant survival benefit in older NDMM patients on protease inhibitor therapy in this study, which was inconsistent with other investigators [16-19]. Moreover, the remission rate with bortezomib was not consistent with the OS in our study. One possible explanation for such differences is the fact that the patients of the current study came from a myeloma medical research center and most of the patients were end-stage or with many other poor prognostic factors, such as with higher incidence of EMP. An alternative explanation is that elderly patients have poor tolerance to chemotherapy; in addition, poor compliance also contributes interruption of treatment or inability to adhere to maintenance therapy.

\section{Conclusions}

In general, the current results provide evidence that bortezomib-containing regimens has a deeper response than thalidomide regimens in elderly MM patients, especially in patients of age older than 75 years; however, it cannot overcome the negative influence on survival of age and MM with EMP.

\section{Consent}

Written informed consent was obtained from the patient for the publication of this report and any accompanying images.

\section{Abbreviations \\ AEs: adverse events; CR/nCR: complete remission/near-complete remission; CT: computed tomography; DS: Durie-Salmon staging system; EMP: extramedullary plasmacytoma; FISH: fluorescence in situ hybridization; Ig: immunoglobulin; ISS: International staging system; MM: multiple myeloma; MRI: magnetic resonance imaging; ORR: overall response rate; OS: overall survival; PFS: progression-free survival; PR: partial remission.}

\section{Competing interests}

The authors declare that they have no competing interests.

\section{Authors' contributions}

$\mathrm{ZH}$ conducted the study, designed the concept, and wrote the paper. NA and XL performed data collection and analysis and had the same contribution to this manuscript. All authors read and approved the final manuscript.

\section{Acknowledgements}

We also thank Dr. SK Kumar for providing guidance to modify and editorial assistance. We also thank Dr. Robert A. Kyle for detailed comments on our manuscript.

Received: 3 March 2015 Accepted: 14 July 2015

Published online: 07 August 2015

\section{References}

1. Kyle RA, Rajkumar SV. Multiple myeloma. Blood. 2008;111(6):2962-72

2. Kim K, Lee JH, Kim JS, Min CK, Yoon SS, Shimizu K, et al. Clinical profiles of multiple myeloma in Asia-An Asian Myeloma Network study. Am J Hematol. 2014;89(7):751-6.
3. Lee JH, Lee DS, Lee JJ, Chang YH, Jin JY, Jo DY, et al. Multiple myeloma in Korea: past, present, and future perspectives. Experience of the Korean multiple myeloma working party. Int J Hematol. 2010;92(1):52-7. PMID: 20544403.

4. Huang SY, Yao M, Tang JL, Lee WC, Tsay W, Cheng AL, et al. Epidemiology of multiple myeloma in Taiwan: increasing incidence for the past 25 years and higher prevalence of extramedullary myeloma in patients younger than 55 years. Cancer. 2007;110(4):896-905. PMID: 17594697.

5. Kumar SK, Dispenzieri A, Lacy MQ, Gertz MA, Buadi FK, Pandey S, et al. Continued improvement in survival in multiple myeloma: changes in early mortality and outcomes in older patients. Leukemia. 2014;28(5):1122-8.

6. Bringhen S, Mateos MV, Zweegman S, Larocca A, Falcone AP, Oriol A, et al. Age and organ damage correlate with poor survival in myeloma patients: meta-analysis of 1435 individual patient data from 4 randomized trials. Haematologica. 2013;98:980-7.

7. Zhang J, Zhong Y. Clinical analysis of 36 multiple myeloma patients with extramedullary plasmacytoma invasion of the spinal canal. Hematol Oncol. 2014. doi:10.1002/hon.2126. [Epub ahead of print]. PMID:24395149.

8. An G, Xu Y, Shi L, Shizhen Z, Deng S, Xie Z, et al. Chromosome 1q21 gains confer inferior outcomes in multiple myeloma treated with bortezomib but copy number variation and percentage of plasma cells involved have no additional prognostic value. Haematologica. 2014;99(2):353-9.

9. Chen HF, Wu TQ, Li ZY, Shen HS, Tang JQ, Fu WJ, et al. Extramedullary plasmacytoma in the presence of multiple myeloma: clinical correlates and prognostic relevance. Onco Targets Ther. 2012;5:329-34.

10. Palumbo A, Mina R. Management of older adults with multiple myeloma. Blood Rev. 2013;27:133-42.

11. Fayers PM, Palumbo A, Hulin C, Waage A, Wijermans P, Beksaç M, et al. Thalidomide for previously untreated elderly patients with multiple myeloma: meta-analysis of 1685 individual patient data from 6 randomized clinical trials. Blood. 2011;118(5):1239-47.

12. Mateos MV, Richardson PG, Schlag R, Khuageva NK, Dimopoulos MA, Shpilberg $\mathrm{O}$, et al. Bortezomib plus melphalan and prednisone compared with melphalan and prednisone in previously untreated multiple myeloma: updated follow-up and impact of subsequent therapy in the phase III VISTA trial. J Clin Oncol. 2010;28:2259-66.

13. San Miguel JF, Schlag R, Khuageva NK, Dimopoulos MA, Shpilberg O, Kropff M, et al. Bortezomib plus melphalan and prednisone for initial treatment of multiple myeloma. N Engl J Med. 2008;359:906-17.

14. Mateos MV, Oriol A, Martínez-López J, Gutiérrez N, Teruel Al, de Paz R, et al. Bortezomib, melphalan, and prednisone versus bortezomib, thalidomide, and prednisone as induction therapy followed by maintenance treatment with bortezomib and thalidomide versus bortezomib and prednisone in elderly patients with untreated multiple myeloma: a randomised trial. Lancet Oncol. 2010;11:934-41.

15. Bringhen S, Mateos MV, Zweegman S, Larocca A, Falcone AP, Attal M, et al. Chromosomal abnormalities are major prognostic factors in elderly patients with multiple myeloma: the intergroupe francophone du myélome experience. J Clin Oncol. 2013;31:2806-9.

16. Gay F, Larocca A, Wijermans P, Cavallo F, Rossi D, Schaafsma R, et al. Complete response correlates with long-term progression-free and overall survival in elderly myeloma treated with novel agents: analysis of 1175 patients. Blood. 2011;117:3025-31.

17. Morabito F, Bringhen S, Larocca A, Wijermans P, Victoria Mateos M, Gimsing $P$, et al. Bortezomib, melphalan, prednisone (VMP) versus melphalan, prednisone, thalidomide (MPT) in elderly newly diagnosed multiple myeloma patients: a retrospective case-matched study. Am J Hematol. 2014;89:355-62.

18. Mikhael JR, Dingli D, Roy V, Reeder CB, Buadi FK, Hayman SR, et al. Management of newly diagnosed symptomatic multiple myeloma: updated Mayo Stratification of Myeloma and Risk-Adapted Therapy (mSMART) consensus guidelines 2013. Mayo Clin Proc. 2013;88:360-76.

19. Palumbo A, Bringhen S, Ludwig H, Dimopoulos MA, Bladé J, Mateos MV, et al. Personalized therapy in multiple myeloma according to patient age and vulnerability: a report of the European Myeloma Network (EMN). Blood. 2011;118:4519-29. 